\title{
Current Perspective on Dominant Negative Mutations: Trends, Scope and Relevance
}

\author{
Mayank Chaudhary ${ }^{1}$, Sidhartha Dan ${ }^{1}$, Varruchi Sharma ${ }^{2}$ (D), Anil Kumar Sharma ${ }^{1,}$ * (D) \\ 1 Department of Biotechnology, Maharishi Markandeshwar (Deemed to be University), Mullana-Ambala-133207, Haryana, \\ India \\ 2 Department of Biotechnology, Sri Guru Gobind Singh College, Sector 26 Chandigarh, India \\ * Correspondence: anibiotech18@gmail.com (A.K.S.)
}

Scopus Author ID 55693618000

Received: 26.11.2020; Revised: 20.12.2020; Accepted: 28.12.2020; Published: 30.12.2020

\begin{abstract}
Despite the advancements in tools and technologies implicated in identifying and characterizing novel genes, there are still a significant number of unknown function proteins. Moreover, the practices employed in order to characterize such proteins have proven to be a futile exercise so far because of many limitations associated with such traditional approaches. Dominant-negative mutations have shown great promise in this direction as the introduction of mutation in the target protein may abolish the protein function and inhibit the function of the simultaneously expressed wild-type protein. These dominant mutations have broader applications in biological processes to study various proteins in terms of their functional aspects, etiological factors, and mechanism of action, paving the way to diagnose many dreadful diseases, including cancer. Considering these facts, the current review emphasizes utilizing the full potential of such dominant-negative mutations in deciphering protein functions and their broad-spectrum applications in biology.
\end{abstract}

Keywords: dominant-negative mutation; antimorph; haploinsufficiency; functional mutation.

(C) 2020 by the authors. This article is an open-access article distributed under the terms and conditions of the Creative Commons Attribution (CC BY) license (https://creativecommons.org/licenses/by/4.0/).

\section{Introduction}

Mendel, based on his observations with respect to flower color, provided a brief description of dominant alleles. With time, the study of genetics matured, and dominance is referred to as alleles whose phenotype is manifested in heterozygous condition. Dominant alleles can also be determined phenotypically when present along with two or more recessive alleles (e.g., R/r/r) as encountered in transgenic strains. Mutations may or may not produce deterministic phenotypic characters. Mutations are known to play a pivotal role in both normal and abnormal biological processes. These are broadly classified as (1) spontaneous mutations (2) mutations due to error-prone replication (3) errors introduced during DNA repair, and (4) induced mutations caused by mutagens [1]. For the sake of experimentation, scientists have deliberately introduced mutant sequences through DNA manipulation. Various ways have been postulated to classify mutations based on structure, function, fitness (harmful or beneficial), inheritance, and impact on the protein sequence.

Mutations can also be classified based on impact on protein function, as shown in table 1. The impact of functional mutation can be beneficial or detrimental, and loss of function can be amorphic or hypomorphic. Hypomorphs are usually recessive but can be dominant occasionally due to haploinsufficiency, where a single functional copy of a gene does not produce enough protein resulting in the abnormal or diseased state. It is responsible for some 
of the autosomal dominant disorders. However, the gain of function may give rise to hypermorphic, anti morphic, and neomorphic mutations. Antimorphs are dominant-negative mutations acting antagonistically to normal gene activity. The phenotypic severity of an antimorph is worse in heterozygous conditions. The increase can reduce it in wild-type gene function [2]. The functionality of protein dimer consisting of normal and mutated protein might also be affected by anti morphic mutation (Fig. 1). Altered gene product from such mutations acts antagonistically to the wild-type protein. These mutations usually result in inactive protein showing dominant or semi-dominant phenotype. The role of dominant-negative mutations in cancer-related genes like p53 [3], ATM, CEBPA, and PPAR gamma has been found in humans [4-6]. Detail of various dominant-negative mutations in humans is compiled in the OMIM database (Table 2).

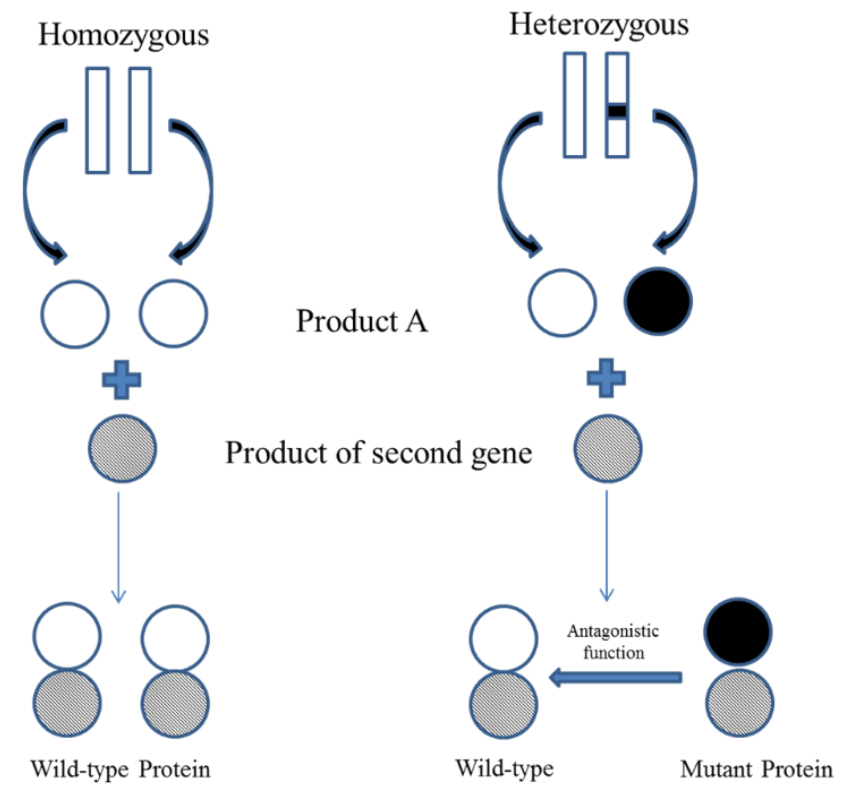

Figure 1. Role of Dominant-negative mutation on multimeric proteins.

\subsection{Dominant mutations: dominant-negatives versus haploinsufficiency.}

Mutations acting as dominant may not behave the same. This article focuses on two such mutations: Dominant-negative and Haploinsufficiency, and mechanistic insights on how these mutations confer a dominant phenotype. Dissimilar dominant alleles may require different mapping strategies. Different situations that could give rise to various types of dominant alleles will be discussed considering the hypothetical dap-1 gene.

\section{Dominant-negative alleles}

An allele can show dominant, semi-dominant, or recessive function depending on the accomplice allele and phenotype considered. For clarification, consider alleles $\mathrm{C}$ and $\mathrm{D}$, with genotypes $\mathrm{CC}, \mathrm{CD}$, and DD. Observation of specific phenotypic characters in $\mathrm{CC}$ and $\mathrm{CD}$ genotypes contradictory from $\mathrm{DD}$ genotype proves that allele $\mathrm{C}$ is dominant to allele $\mathrm{D}$. On the contrary, allele $\mathrm{C}$ and $\mathrm{D}$ are considered co-dominant if $\mathrm{CD}$ phenotype is in the middle or joins characters from both CC and DD phenotype [2,7].

Huntington's disease gives an uncommon example of the freak allele that is predominant to wild-type as homozygotes are less influenced than heterozygotes [8-11]. Huntington protein interacts with over 100 other proteins and appears to have multiple biological functions [12]. The behavior of this mutated protein is not completely understood. 
However, it is toxic to certain cell types, particularly the brain. Early damage is most evident in the striatum. However, other areas of the brain are also more conspicuously affected by the progression of the disease. Early symptoms are attributable to the striatum functions and its cortical connections that control movement, mood, and higher cognitive function $[13,14]$. Huntington's disease might also involve epigenetic alterations like DNA methylation and histone modification $[15,16]$.

\subsection{Special role of dominant mutations on behalf of their functional determination potential.}

Dominant-mutations can have both detrimental as well as beneficial effects on biological research. As so far, the disease-causing effects of dominant mutations have been observed, but that does not mean that these mutations cannot be used for biological research. The following section considers this point where the first part will cover such mutations' role to determine or ascertain the function of highly conserved genes with specific examples. The second part will focus on the gain of function research and the concerns behind it.

Table 1. Mutations based on protein function.

\begin{tabular}{l|l} 
Types & Characteristics \\
\hline Amorph & Complete loss of protein \\
\hline Hypomorph & Reduction in protein function \\
\hline Hypermorph & Increase in protein function \\
\hline Neomorph & Development of new function \\
\hline Antimorph/Dominant-negative & Mutant protein interferes with wild-type protein
\end{tabular}

Table 2. Few examples of Dominant-negative mutations in humans (OMIM Database).

\begin{tabular}{l|l|l}
$\begin{array}{l}\text { OMIM } \\
\text { Number }\end{array}$ & $\begin{array}{l}\text { Gene, Protein } \\
\text { Phenotype }\end{array}$ \\
\hline 173110 & GHR, growth hormone receptor & Laron syndrome \\
\hline 139250 & GHI, growth hormone 1 & Pituitary hormone deficiency \\
\hline 190160 & THRB, thyroid hormone receptor $\beta$ & Growth hormone deficiency \\
\hline 138850 & GNRHR, gonadotropin-releasing hormone receptor & Thyroid hormone resistance \\
\hline 165230 & GLI2, GLI, Kruppel family member 2 & $\begin{array}{l}\text { Hypogonadotropic hypogonadism } \\
\text { without anosmia }\end{array}$ \\
\hline 191740 & UGT1A1, UDP glycosyltransferase 1 superfamily & Culler-Jones syndrome \\
\hline 191170 & TP53, tumor protein p53 & Gilbert syndrome \\
\hline 600140 & CREBBP, CREB- binding protein & Li-Fraumeni syndrome \\
\hline 194070 & WT1, Wilms tumor 1 & Rubinstein-Taybi syndrome \\
\hline
\end{tabular}

2.2. Use of dominant negatives in the determination of cellular function.

Candida albicans (C. albicans) cause more serious infections than any other fungus, but because of its diploid genome and lack of sexual reproduction, it becomes difficult to study this organism using classical genetics. Till now, many powerful molecular methods have been developed for studying biology and pathogenesis caused by C. albicans, but still, many fundamental questions cannot be concretely answered using cloning and gene disruption. Pathways for protein trafficking are highly conserved in all eukaryotes. Detailed studies have been carried out on Saccharomyces cerevisiae to study this secretion pathway. Dozens of $S$. cerevisiae genes encoding key components, especially those controlling the pathway mentioned above, have been cloned to analyze the details [17-19]. C. albicans exhibit homology with $S$. cerevisiae secretion pathway genes, hence $C$. albicans homologs (SEC18, SEC14, and SEC4) [20-22] of three essential S. cerevisiae secretion pathway genes have been the target of extensive study. All of these three genes complement the corresponding mutations in $S$. cerevisiae, and their deduced protein products corresponding to $S$. cerevisiae have been 
found to be 50-67\% identical [21]. In S. cerevisiae, SEC4 encodes a small Ras-like GTPase ( $\operatorname{Sec} 4 \mathrm{p})$, which is required for the fusion of post-Golgi secretory vesicles to the plasma membrane [23]. As the SEC4 gene is essential for S. cerevisiae therefore, sec4 null mutants are nonviable. Dominant-negative mutations in S. cerevisiae SEC4 gene leads to inhibition of growth and protein secretion and cause post-Golgi secretory vesicles to accumulate intracellularly [24]. The role of the SEC4 gene in C. albicans was highlighted by Mao et al. [25] by cloning homolog of SEC4 after complementation of temperature-sensitive $S$. cerevisiae sec 4 mutant and using site-directed mutagenesis to successfully construct mutant sec4 allele which was analogous to those encoding trans-dominant inhibitors of other ras-like GTPases. Their study observed that the sec 4 mutant phenotype could be induced even if there was the presence of two wild-type SEC4 alleles, which indicated the role of sec4 (S28N) as a dominantnegative mutant allele. The study proved pivotal as sec4 $(\mathrm{S} 28 \mathrm{~N})$ overexpression was not able to inhibit growth and protein secretion in a minority of galactose-incubated transformants. Secondly, phenotype exhibiting growth inhibition was lost after prolonged incubation in galactose. Their results concluded that the SEC4 gene in C. albicans is primarily required for proper growth and protein secretion. However, it functions at later stages in the protein secretion pathway than the formation of post-Golgi secretory vesicles [25].

\subsection{Typical examples of dominant-negative mutations.}

Dominant-negative effects have been related to proteins involved in signaling and transcriptional activity. A specific example is provided by Drosophila's dorsal (dl) protein's DNA binding activity, which depends on dimerization. Most mutations are true recessives, but one particular mutation exerts a dominant-negative effect. This is an Arg-*Cys substitution that maps to the DNA binding domain but does not affect oligomerization. It appears to act by abolishing the DNA binding of normal/mutant heterodimers [26]. Another example of a dominant-negative mutation in Drosophila is Abruptex $(A x)$ missense mutation at Notch locus $[27,28]$. Similarly, the more severe phenotype associated with Wilms tumor (WT1) mutation in Denys-Drash syndrome, as compared with Wilms's a tumor/genitourinary abnormalities, may be explained by the dominant-negative behavior of specific zinc finger mutations in the former condition. It is not yet certain whether this is mediated by WT1 dimers [29,30].

Dominant-negative mutation in KIT proto-oncogene results in pigmentation related disorder manifested as white spotting (W) in mouse [31] and piebaldism in humans [32]. KIT encodes receptor tyrosine kinase, which undergoes dimerization in response to ligand binding to pursue its activity. There can be a severe phenotype of piebaldism depending upon the type of mutation. Frameshift mutation resulted in a mild phenotype in heterozygous condition, which was supposed to be attributed to haploinsufficiency. Splice junction mutation affected intracellular tyrosine kinase domain, inhibiting signal transduction and increasing the disease [32]. The dominant-negative effect is seen as a contributory factor resulting in variable phenotype through truncations in the same domain as seen in an analogous truncation of fibroblast growth factor receptor (FGF-R) [33].

Dominant-negative effects can also be very useful in the case of neoplasia. Mutation in tumor suppressor gene (p53) might result in neoplastic growth [34]. Although p53 is conventionally viewed as a "recessive" tumor suppressor gene, some mutants can deregulate p53 function in a dominant-negative fashion. A large number of p53 mutations have been described, but most of them are missense mutations concentrated in four hotspots [35]. Some of these mutations can change the conformation of p53. In in-vitro conditions, p53 can adopt 
either active or inactive conformation; wild type protein is normally in an active state. Cotranslation with certain missense mutants results in mixed oligomers that adopt the inactive conformation [36]. In contrast, no alteration in wild-type activity is induced by co-translated missense mutant associated with the Li-Fraumeni syndrome suggesting that Li-Fraumeni p53 mutants may be relatively weak. It should be noted that p53 oligomerization domain lies at the extreme C-terminus, so prematurely truncated forms cannot bind wild type and therefore cannot act in a dominant-negative fashion.

Herskowitz described two models for the dominant-negative effect [37]. Mutant protein can either show toxicity in a multimeric complex or compete with wild-type to bind the target factors. Representatives of both classes are known to be an example of the first model of negative regulation by forming inactive heterodimers of transcription factors MyoD and c-Jun by Id and JunB proteins, respectively. Id protein is a truncated helix-loop-helix (HLH) protein that forms a dimer with MyoD but lacks the basic region required for DNA binding [38]. Similarly, critical amino acid substitution in JunB results in the formation of inactive JunB/cJun heterodimer rather than its homo-dimerization [39]. The second model is explained by the interferon activator (IRF1) and its antagonist (IRF2). IRF2 has enhanced DNA binding potential and displaces IRF1 from the interferon promoter but acts as a weak activator [40].

\section{Haploinsufficiency}

This condition is where a single functional allele is not enough to provide functional protein when the other copy is compromised. This leads to loss of function and gives this mutation the name of haploinsufficiency. This situation will be clarified using hypothetical dap-1gene. Assume that a certain threshold activity of dap-1 is essential to avoid the abnormal phenotype P1. To achieve this threshold level, two copies of wild-type genes are required. Mutations occurring in the dap-1, which can reduce or eliminate its activity, would therefore behave dominantly. This is because, in the heterozygous animals, the remaining single wildtype allele of the dap-1 gene will exhibit insufficient levels to exhibit wild-type gene activity.

Hence the loss-of-function on the dap-1 mutant allele (dap-1) may produce a similar phenotype whether present in one or two copies, behaving dominantly. Contrarily, dap-1/dap1 heterozygous animals shall exhibit a phenotype that differs quantitatively or qualitatively from homozygous dap-1/dap-1 animals because the former case still produces half of the normal gene dose.

\subsection{Haploinsufficiency as an emerging cause of diseases and their complications.}

Various diseases, especially syndromes, arise and/or complicate on account of genetic defects and mutations. Dominant mutations are no exception to this, but detection of their specific role and mechanism has always been a challenge to the researchers, as seen in the case of haploinsufficiency. Haploinsufficiency has been found to be closely related to a number of diseases, including cancer, as per recent reports [41].

a) Role of haploinsufficiency in CRIMI gene that codes for cysteine-rich motor neuron 1 protein resulted in defects in human and mice eye development as reported by Beleggia et al. [42]. Some additional reports also have a related role of gut microbiota to neurological disorders and other health risks [43,44].Colobomatous macrophthalmia with microcornea syndrome (MACOM) is an autosomal dominant malformation of the eye characterized by (1) microcornea with increased axial length (2) coloboma of the iris and of the optic disc, and (3) 
severe myopia. Role of CRIM1 gene during eye development in mice was targeted through a cross between the Crim $1^{\text {flox }}$ mouse line and Ap $2 \alpha$-cre mouse line. Results showed alterations of eye development in homozygous mice resulting in severe morphological changes. These findings were synonymous with anomalies observed in MACOM patients and confirmed CRIM1 gene as a causative agent for MACOM syndrome. This further emphasized that haploinsufficiency of CRIM1 may cause abnormality in eye development [42].

b) Similar role of haploinsufficiency was found in the $M Y B P C 3$ gene that codes for cardiac myosin binding protein-C. This protein is a special component of thick filaments forming striated muscles. Studies suggest that MyBP-C may have both structural and regulatory roles within the sarcomere $[45,46]$. The physiologically significant role of MyBP-C has also been found as mutations in $M Y B P C 3$ were identified as one of the most common causes of hypertrophic cardiomyopathy (HCM) $[47,48]$. Out of these, approximately two-thirds of $M Y B P C 3$ mutations are predicted to generate truncated protein [49,50]. Till recent times it was unpredictable whether the autosomal dominant nature of $M Y B P C 3$ mutations results from haploinsufficiency or poison peptide effect (on the virtue of which the mutant proteins interfere with normal sarcomere function). It has always been a rationale statement to the research community that most of the sarcomere gene mutations causing HCM are the missense alleles that encode dominant negative proteins. However, mutations in MYBPC3 exist as few exceptions because it frequently encodes truncated proteins. Marston et al. [51] and others [52] tried to determine the evidence of haploinsufficiency in $M Y B P C 3$ mutations causing hypertrophic cardiomyopathy. Their study highlighted that in human myectomy samples with MYBPC3 truncation mutations, no detectable amount of truncated MyBP-C protein was found in either incorporated or unincorporated form. Analysis of heart samples of patients bearing MYBPC3 mutations revealed 24\% lower MyBP-C content. This strongly argues for haploinsufficiency as the disease mechanism for both truncation and missense mutations similar to earlier observations [53-55]. It also argued against the incorporation of truncated MyBP-C protein to cause any dominant-negative effect due to the absence of any detectable truncated MyBP-C.

c) Haploinsufficiency event might shape the disease and complicates it to a much severe degree, as seen in the case of mucinous cystic neoplasms (MCNs). Izeradjene et al. [56] reported from their study that concomitant expression of Kras ${ }^{\mathrm{G} 12 \mathrm{D}}$ and haploinsufficiency of Smad4/Dpc4 tumor suppressor gene instigate a whole new class of pancreatic tumors known by the name of mucinous cystic neoplasms (MCNs). The disease's progression was found to be accompanied by loss of heterozygosity of Dpc4 and mutation in either of the p53 or p16 gene $[57,58]$.

\subsection{Role of haploinsufficiency in disease modification.}

a) Modification of EGFR driven tumorigenesis through Trp53 haploinsufficiency: Alteration in expression levels of TP53 and EGFR genes is seen in malignant peripheral nerve sheath tumors (MPNSTs), which belongs to a class of aggressive sarcomas. In this regard, Rahrmann et al. [47] worked on determining co-operation between underexpression of cell cycle regulator TP53 gene and over-expression of epidermal growth factor receptor (EGFR) gene for the transformation of Schwann cell in-vitro and formation of MPNST in-vivo. The collective results, which comprised human gene copy number alteration data, microarray data, and thrombotic microangiopathies (TMA) data, indicated co-occurrence of EGFR overexpression TP53 haploinsufficiency in human MPNST samples. Simultaneously, in-vivo 
studies on transgenic mice over-expressing EGFR in Schwann cells and heterozygous for Trp53-null allele showed a significant increase in MPNST formation.

b) Haploinsufficiency of BRCA1: Breast cancer has always been a challenge to cancer biology experts. The tumor suppressor gene $B R C A$ is what they study extensively to find therapeutic measures against the disease. BRCA1 and BRCA2 genes expressed in breast and other tissue cells have physiological importance of repairing damaged DNA or destruction of affected cells if the damage is beyond repair. Mutation in either of these genes is responsible for the majority of breast cancer cases [59,60]. Numerous mutations of $B R C A 1$ gene have been identified, and many have shown an association with increased risk of cancer. A recent study by Feilotter et al. [61] related BRCAl haploinsufficiency with alteration in gene expression that functions in cellular proliferation and development. The researchers developed a biological assay for haploinsufficiency of $B R C A l$ where they compared the expression pattern of genes in BRCAl wild-type cells with those carrying (heterozygous) BRCAl pathogenic mutations. They identified a subset of 43 genes whose combined expression pattern can be used as a predictor of BRCA1 status. This subset comprised of genes involved in cellular differentiation. Their study concluded that single copy loss of BRCAl function might affect differentiation making cells more susceptible to malignancy. However, BRCAl haploinsufficiency at lower doses may not cause DNA damage at a global level but facilitates such change at higher doses.

Consistent with the findings from other studies, down-regulation of interferon regulated genes in BRCA1+/- cells highlighted the role of BRCAl haploinsufficiency in the deregulation of interferon signaling [61]. Earlier studies on breast tumors of BRCAl carriers reported a higher rate of $\mathrm{LOH}$ of wild-type allele [62-64]. However, there exists a few cases where tumor tissue exhibits loss of the mutant allele and normal tissue shows LOH of the wild type BRCA1 allele. Few studies also support the complete loss of $B R C A 1$ in sporadic cancer as a rare event $[65,66]$. However, a different mechanism might be involved in $B R C A 1$ inactivation in sporadic cancer, or $B R C A 1$-dependent oncogenesis is associated with haploinsufficiency during initial developmental stages.

\subsection{Variants of haploinsufficiency in various cancer types.}

Gene over-expression or increased dosage has been commonly accepted as one of the causative events in cancer formation. Surprisingly, there exist a number of evidence for the role of haploinsufficiency in oncogenic events, but still, this concept has lagged far behind in relation to cancer. Cancer biologists consider proto-oncogenes and tumor suppressor genes (TSG) as two broad classes of high penetrance genes mutated in cancer [67-70]. Oncogenes are known to be activated by dominant mutations that enhance the function of a gene product. In contrast, tumor suppressors must be fully inactivated to initiate tumor progression. Hence, it was expected that mutations in these genes would act in a recessive manner. The concept of recessive TSG function in cancer was explained using the 'two-hit' hypothesis [71,72]. Due to the high probability of the second hit, it was supposed that the cancer susceptibility syndrome was inherited dominantly, but mutations in a recessive gene caused it. This informative theory led the two-hit hypothesis as the beginning of TSG identification generations such as BRCAl, $A P C, B R C A 2$, and $V H L$ [63,73-75]. Finally, it helped identify p53 as a tumor suppressor gene rather than an oncogene [76,77].

a) TSG haploinsufficiency in tumor formation with an example of p53: Two broad classes of TSGs have been identified as gatekeepers and caretakers. Caretaker genes (e.g. p53) prevent or repair the damage that occurred in the genome, thereby reducing the rate of mutation 
acquisition and cancer. The gene $p 53$ is found to be mutated in at least $50 \%$ of human cancers and may prove higher in several cases [78-81]. Though $p 53$ is now considered a potent TSG it was not always the case when initial studies of $p 53$ suggested that it exhibit oncogenic properties [82-85]. Few published studies indicated that oncogenic properties resulted from mutations in wild-type tumor-suppressor $p 53$ [86-88]. Such mutations are responsible for the formation of truncated proteins resulting in deregulation of gene function. In some cases, this mutation acts as a dominant-negative for wild-type $\mathrm{p} 53$ protein as they stabilize the normally labile p53 protein. The p53 locus is prone to deletion, as in human cancer, and loss of heterozygosity ( $\mathrm{LOH})$ appears in a few tumors docking p53 mutation [89]. The haploinsufficiency of $p 53$ in promoting tumorigenesis is seen as a loss of one copy of p53 gene, which gives rise to an intermediate phenotype. Certain other genes such as PTEN exhibit the property of 'obligate haploinsufficiency' where heterozygous state promotes a greater degree of cancer than a homozygous state. The hint of haploinsufficiency in p53 was found by analyzing Li-Fraumeni syndrome patients (LFS) [90]. Germ-line mutations cause the majority of LFS cases in p53 [91,92]; generally, these are missense mutations, but deletions can also occur, resulting in truncated proteins. Study based on analysis of tumors from LFS patients focussed on LOH of TP53 gene. Approximately 60\% of the tumors analyzed revealed LOH at p53 locus [93], highlighting that single-copy loss of TP53 could contribute to tumorigenesis rather than the previous belief of $p 53$ mutations acting as dominant-negative inhibitors of the wild-type allele. To address this issue, tumors were analyzed from $p 53$ allele knockout mice. It was observed that homozygous p53 knockout (-/-) animals are viable but readily develop several types of tumor. Lethality appears by the age of 10 months. The survival of $p 53$ heterozygote $(+/-)$ animals was intermediate to wild-type $(+/+)$ and $(-/-)$ animals. These heterozygous $p 53(+/-)$ animals develop tumors that do not exhibit loss or mutation of the remaining $p 53$ allele [94]. This shows that heterozygosity of $p 53$ is sufficient for tumorigenesis [95].

This fact was further supported by the study based on quantifying the transcriptional response to in-vivo p53 expression using transgenic p53-reporter mouse strain [96]. These animals had transgene in which expression of lacZ reporter was driven by $p 53$-responsive promoter 'Mdm2'. Researchers working on this model noticed that $p 53(+/-)$ embryos carrying this transgene exhibited severely low lacZ activity. This observation concluded that p53 levels prove to limit for transcription of target genes. Hence, TP53 gene can be considered haploinsufficient in such cases [96].

These studies, including several others, indicate that $p 53$ haploinsufficiency is capable on its own to promote cancer and TP53 expression levels prove pivotal for tumor initiation and progression.

b) Haploinsufficiency in another TSG (PTEN): Like TP53 another TSG, 'PTEN' which codes for Phosphatase and tensin homolog (PTEN) protein, is involved in suppression of numerous cancer types. PTEN is mutated or lost in a large fraction of human cancers, including breast cancer, endometrial cancer, prostate cancer, colon cancer, and glioblastoma [97]. Numerous studies from human and mice models provide evidence to support the role of PTEN haploinsufficiency in the promotion of cancer. In addition to this, PTEN haploinsufficiency is co-related with other genetic events to promote prostate cancer [59,98-100]. In contrast to $p 53$, $P T E N$ functions as gatekeeper and negatively regulates proliferation signals [101-104]. As discussed above, PTEN defines a case of 'obligate haploinsufficiency' where loss may give rise to gain when it comes to tumor suppression. Two independent studies suggested this that 
complete loss of PTEN may actually be less tumorigenic than a heterozygous loss of PTEN [105-107].

The explanation for this seems complex but is based on multiple gene interactions. Complete loss of PTEN expression activates TP53-dependent cellular response, which in turn acts as a brake for tumor formation [105]. In contrast to this, heterozygous loss of PTEN can enhance proliferation and acts more as tumorigenic. Mutated TP53 cells that are markedly unable to activate p53 do not undergo PTEN loss-induced cellular senescence [108], and hence complete PTEN loss proves more tumorigenic than the partial loss of the gene. These findings suggest that complete loss of PTEN cooperates with partial or complete loss of TP53. Thus, PTEN clearly validates a new theory of 'obligate haploinsufficiency'. As evident from the examples given above, the mechanism depends on the conditions, hence the theory becomes conditional.

Another complex situation is of 'compound haploinsufficiency', where haploinsufficiency of multiple genes in the region cooperates together and promotes tumorigenesis. In this case, a single gene alone is not capable of promotion or initiation of tumorigenesis, but heterozygosity of that particular gene in co-operation with another results in haploinsufficiency and cancer development. This situation can be symmetric or asymmetric. Asymmetric haploinsufficiency occurs when haploinsufficiency of one gene promotes the phenotype expressed by another gene but not vice-versa. This condition was exemplified by Ma et al. [109], which enlightened asymmetrical haploinsufficiency in tumor suppression because of functional interaction of PTEN and Tsc2 genes in mice.

\subsection{Understanding haploinsufficiency in terms of cell proliferation and regulation.}

Deregulation of cell polarity proteins has always been closely associated with invasion and metastasis processes. TRIM62 gene, also called DEAR1 (for ductal epithelium-associated RING chromosome 1) is a regulator of cell polarity. It acts as a tumor suppressor gene, majorly in breast cancer.

a) Haploinsufficiency of TRIM62: Quintás-Cardama et al. [110] examined the role of TRIM62 in the development of lung cancer and found that haploinsufficiency of TRIM62 cooperatively acts with K-RasG12D mutation promoting invasiveness and disruption of 3-d morphogenesis affecting epithelial-mesenchymal transitions. They also noted that these phenotypes in tumor cell lines are reverted on the re-expression of TRIM62. Thus, they concluded that decreased levels of TRIM62 may play an important role in the evolution of lung cancer, as evident from their results [99].

b) NBS1 haploinsufficiency: Hypomorphic mutations cause Nijmegen breakage syndrome (NBS), which is a rare human autosomal recessive disorder. It accounts for the virtue of mutations in NBS1 gene that causes a defect in resection of double-strand breaks. NBS1 physiologically acts as a part of MRN complex, which is a protein complex and functions both in homologous recombination (HR) and non-homologous end-joining (NHEJ). NBS is characterized at a cellular level by chromosomal breakage and defective cell cycle checkpoints. NBS1 null mutations exhibit early embryonic lethality in mice, whereas hypomorphic mutants of NBS1 are viable. Cells from these mice have defective $S$ phase and G2/M checkpoints. Polymorphisms of NBS1 have been found associated with an increased risk of breast cancer in humans [111]. Studies have found the pivotal role of NBS1 in the clinical outcome of breast cancer in patients, but NBS1 haploinsufficient mouse results in rare mammary tumors. For clarification, Wan et al. [112] examined the role of NBS1 in mammary tumorigenesis using 
NBS1+/- mice crossed with mammary tumor-prone MMTV-neu transgenic strain. They observed an increased level of mammary tumor latency in $N B S 1+/-$; neu mice compared to $\mathrm{NBS1+/+;}$ neu control animals due to increased apoptosis in early $N B S 1+/-$; neu mammary tumors. However, a strong metastasis level was observed in NBS1+/-; neu mammary tumors, thereby exhibiting a differential gene expression profile compared to control tumors. The authors thus reported increased mammary tumor latency and metastasis due to NBS1 haploinsufficiency.

c) Haploinsufficiency in KISS1 receptor (GPR54) and Sam68: Effect of haploinsufficiency to cause a delay in breast tumor initiation, progression, and lung metastasis was studied by Cho et al. [113], targeting KISS1 receptor (KISSR or GPR54). KISS1R on activation with Kisspeptins functions in normal physiology and pathophysiology. KISS1R signaling has been associated with the inhibition of tumor angiogenesis and metastasis, but the role of KISSIR haploinsufficiency in tumorigenesis was recently explored [113]. They developed PyMT/Kiss1r mice by crossing Kiss $1 r$ heterozygous mouse (kiss $1 r+/-)$ with MMTV-PyMT transgenic mouse and observed that Kiss $1 r$ heterozygosity in MMTVPyMT/Kiss1r+/- mouse model attenuated breast cancer initiation, growth, latency, multiplicity, and metastasis.

An effect similar to KISS1R haploinsufficiency was reported by Richard et al. [114], where Sam68 haploinsufficiency delayed the onset of mammary tumorigenesis and metastasis. Sam68 is an RNA-binding protein often mentioned as STAR (signal transduction activator of RNA) protein. The study proved that Sam68 might act as an in-vivo modulator of tyrosine kinase activity and as an effective signaling molecule required for mammary tumorigenesis and metastasis.

d) Mtbp haploinsufficiency and tumor metastasis promotion: Contrary to the haploinsufficiency results reported above, Iwakuma et al. [115] revealed that Mtbp haploinsufficiency promotes tumor metastasis in mice. Mdm2 acts as an inhibitor of p53, but over-expression of $\mathrm{Mdm} 2$ with wild-type p53 in numerous tumors suggests an alternate mechanism for loss of p53 activity. The protein MTBP (Mdm2-binding protein) inhibits selfubiquitination of Mdm2, leading to stability of Mdm2 and degradation of $\mathrm{p} 53$. The workers in their study used haploinsufficiency model to address the role of MTBP in the regulation of p53 pathway. They observed that sensitization of mice for tumor development by p53 heterozygosity showed significant development of metastatic tumors in $M t b p+/-p 53+/-$ mice compared to $p 53+/-$ mice. The results suggested the role of MTBP as a metastasis suppressor and as a novel therapeutic target for metastasis.

\subsection{Understanding haploinsufficiency about RNA.}

Haploinsufficient TSGs are generally impaired by 50\% reduction in expression, whereas quasi-insufficiency (less than 20\% reduction) of PTEN protein level may also contribute to cancer development [116]. Studies based on mouse models suggest that targeting TP53 by short hairpin RNAs (shRNAs) exhibit distinct phenotypes differing from hyperplasia to malignancy. All of these depend upon a reduction in protein level [117]. So we can conclude that some TSGs, like PTEN are exquisitely dosage-sensitive while others like TP53 are intermediately sensitive.

As discussed earlier, the mutual co-operation of multiple haploinsufficient genes promotes tumorigenesis giving rise to 'compound haploinsufficiency'. A popular example demonstrating the importance of combinatorial interactions exhibiting different phenotypes is 
$5 q$ deletion syndrome [118]. Studies have also shown synergistic tumor growth promotion by co-suppressing TSG genes on chromosome 8p [119]. Genes and even microRNAs (miRNAs) are found to be haploinsufficient to cause developmental abnormalities in humans [120]. Some of the genes like DICERI and XPO5 are involved in miRNA biosynthesis pathway and identified as haploinsufficient tumor suppressors [121,122]. MicroRNAs are also involved in gene regulation at the post-transcriptional level through RNA-induced silencing complex (RISC) either by mediating translational inhibition or by mRNA cleavage resulting in decreased protein level [123]. This aspect has broadened the dimensions of haploinsufficiency with miRNAs' role, leading to the production of an insufficient amount of proteins.

\section{Conclusions}

It is indeed important to understand the etiologic and mechanistic foundation of dominant-negative mutations. Efforts are underway to understand the complex intricacies of protein-protein interaction networks and how dominant-negative mutations could play a role in delineating them. However, the designing of dominant-negative proteins is of paramount importance for enhancing the study of gene function. Many oligomeric proteins in the past have been known to handle a variety of functions simultaneously. However, their defective status sometimes may result in susceptibility to a particular disease as well. Therefore, dominantnegative mutations could be an important tool to understand the association between health and disease.

\section{Funding}

This research received no external funding.

\section{Acknowledgments}

The authors are thankful to the Institute for carrying out his work.

\section{Conflicts of Interest}

The authors declare no conflict of interest.

\section{References}

1. Muller, H.J. Further studies on the nature and causes of gene mutations, Proceedings of the 6th International Congress of Genetics, Ithaca, New York, 1932, 213-255.

2. Wilkie, A.O. The molecular basis of genetic dominance. Journal of medical genetics 1994, 31, 89-98, https://doi.org/10.1136/jmg.31.2.89.

3. Goh, A.M.; Coffill, C.R.; Lane, D.P. The role of mutant p53 in human cancer. J Pathol 2011, 223, 116-126.

4. Chenevix-Trench, G.; Spurdle, A.B.; Gatei, M.; Kelly, H.; Marsh, A.; Chen, X.; Donn, K.; Cummings, M.; Nyholt, D.; Jenkins, M.A.; Scott, C.; Pupo, G.M.; Dörk, T.; Bendix, R.; Kirk, J.; Tucker, K.; McCredie, M.R.E.; Hopper, J.L.; Sambrook, J.; Mann, G.J.; Khanna, K.K. Dominant Negative ATM Mutations in Breast Cancer Families. JNCI: Journal of the National Cancer Institute 2002, 94, 205-215, https://doi.org/10.1093/jnci/94.3.205.

5. Paz-Priel, I.; Friedman, A. C/EBP $\alpha$ dysregulation in AML and ALL. Critical reviews in oncogenesis 2011, 16, 93-102, https://doi.org/10.1615/critrevoncog.v16.i1-2.90.

6. Bonne, G.; Carrier, L.; Bercovici, J.; Cruaud, C.; Richard, P.; Hainque, B.; Gautel, M.; Labeit, S.; James, M.; Beckmann, J.; Weissenbach, J.; Vosberg, H.-P.; Fiszman, M.; Komajda, M.; Schwartz, K. Cardiac myosin binding protein- $\mathrm{C}$ gene splice acceptor site mutation is associated with familial hypertrophic cardiomyopathy. Nature Genetics 1995, 11, 438-440, https://doi.org/10.1038/ng1295-438. 
7. Wu, Z.; Tang, D.; Liu, K.; Miao, C.; Zhuo, X.; Li, Y.; Tan, X.; Sun, M.; Luo, Q.; Cheng, Z. Characterization of a new semi-dominant dwarf allele of SLR1 and its potential application in hybrid rice breeding. Journal of experimental botany 2018, 69, 4703-4713, https://doi.org/10.1093/jxb/ery243.

8. Wexler, N.S.; Young, A.B.; Tanzi, R.E.; Travers, H.; Starosta-Rubinstein, S.; Penney, J.B.; Snodgrass, S.R.; Shoulson, I.; Gomez, F.; Arroyo, M.A.R.; Penchaszadeh, G.K.; Moreno, H.; Gibbons, K.; Faryniarz, A.; Hobbs, W.; Anderson, M.A.; Bonilla, E.; Conneally, P.M.; Gusella, J.F. Homozygotes for Huntington's disease. Nature 1987, 326, 194-197, https://doi.org/10.1038/326194a0.

9. Myers, R.H.; Leavitt, J.; Farrer, L.A.; Jagadeesh, J.; McFarlane, H.; Mastromauro, C.A.; Mark, R.J.; Gusella, J.F. Homozygote for Huntington disease. American journal of human genetics 1989, 45, 615-618, https://doi.org/10.1038/326194a0.

10. Goldstein, O.; Kedmi, M.; Gana-Weisz, M.; Twito, S.; Nefussy, B.; Vainer, B.; Fainmesser, Y.; Abraham, A.; Nayshool, O.; Orr-Urtreger, A.; Drory, V.E. Rare homozygosity in amyotrophic lateral sclerosis suggests the contribution of recessive variants to disease genetics. Journal of the Neurological Sciences 2019, 402, 62-68, https://doi.org/10.1016/j.jns.2019.05.006.

11. Da Prat, G.; Etcheverry, J.L.; Cesarini, M.; Gatto, E. Reader response: Clinical manifestations of homozygote allele carriers in Huntington disease. Neurology 2020, 94, 723, https://doi.org/10.1212/wnl.0000000000009307.

12. Goehler, H.; Lalowski, M.; Stelzl, U.; Waelter, S.; Stroedicke, M.; Worm, U.; Droege, A.; Lindenberg, K.S.; Knoblich, M.; Haenig, C., et al. A protein interaction network links GIT1, an enhancer of huntingtin aggregation, to Huntington's disease. Mol Cell 2004, 15, 853-865, https://doi.org/10.1016/j.molcel.2004.09.016.

13. Walker, F.O. Huntington's disease. The Lancet 2007, 369, 218-228, https://doi.org/10.1016/s01406736(07)60111-1.

14. Rodrigues, F.B.; Quinn, L.; Wild, E.J. Huntington's Disease Clinical Trials Corner: January 2019. Journal of Huntington's disease 2019, 8, 115-125, https://doi.org/10.3233/jhd-190001.

15. Glajch, K.E.; Sadri-Vakili, G. Epigenetic Mechanisms Involved in Huntington's Disease Pathogenesis. Journal of Huntington's disease 2015, 4, 1-15, https://doi.org/10.3233/jhd-159001.

16. Mohd Murshid, N.; Aminullah Lubis, F.; Makpol, S. Epigenetic Changes and Its Intervention in Age-Related Neurodegenerative Diseases. Cellular and molecular neurobiology 2020, https://doi.org/10.1007/s10571020-00979-z.

17. Novick, P.; Field, C.; Schekman, R. Identification of 23 complementation groups required for posttranslational events in the yeast secretory pathway. Cell 1980, 21, 205-215, https://doi.org/10.1016/00928674(80)90128-2.

18. Pryer, N.K.; Wuestehube, L.J.; Schekman, R. VESICLE-MEDIATED PROTEIN SORTING. Annual Review of Biochemistry 1992, 61, 471-516, https://doi.org/10.1146/annurev.bi.61.070192.002351.

19. Lazar, T.; Götte, M.; Gallwitz, D. Vesicular transport: how many Ypt/Rab-GTPases make a eukaryotic cell? Trends in Biochemical Sciences 1997, 22, 468-472, https://doi.org/10.1016/s0968-0004(97)01150-X.

20. Nieto, A.; Sanz, P.; Sentandreu, R.; del Castillo Agudo, L. Cloning and characterization of the SEC18 gene from Candida albicans. Yeast (Chichester, England) 1993, 9, 875-887.

21. Monteoliva, L.; Sánchez, M.; Pla, J.; Gil, C.; Nombela, C. Cloning of Candida albicans SEC14 gene homologue coding for a putative essential function. Yeast (Chichester, England) 1996, 12, 1097-1105, https://doi.org/10.1002/(sici)1097-0061(19960915)12:11\%3c1097::aid-yea990\%3e3.0.co;2-e.

22. Clément, M.; Fournier, H.; de Repentigny, L.; Belhumeur, P. Isolation and characterization of the Candida albicans SEC4 gene. Yeast (Chichester, England) 1998, 14, 675-680, https://doi.org/10.1002/(sici)10970061(199805)14:7<675::aid-yea252>3.0.co;2-9.

23. Salminen, A.; Novick, P.J. A ras-like protein is required for a post-Golgi event in yeast secretion. Cell 1987, 49, 527-538, https://doi.org/10.1016/0092-8674(87)90455-7.

24. Walworth, N.C.; Goud, B.; Kabcenell, A.K.; Novick, P.J. Mutational analysis of SEC4 suggests a cyclical mechanism for the regulation of vesicular traffic. The EMBO journal 1989, 8, 1685-1693.

25. Mao, Y.; Kalb, V.F.; Wong, B. Overexpression of a dominant-negative allele of SEC4 inhibits growth and protein secretion in Candida albicans. Journal of bacteriology 1999, 181, 7235-7242, https://doi.org/10.1128/jb.181.23.7235-7242.1999.

26. Isoda, K.; Roth, S.; Nüsslein-Volhard, C. The functional domains of the Drosophila morphogen dorsal: evidence from the analysis of mutants. Genes Dev 1992, 6, 619-630, https://doi.org/10.1101/gad.6.4.619.

27. Kelley, M.R.; Kidd, S.; Deutsch, W.A.; Young, M.W. Mutations altering the structure of epidermal growth factor-like coding sequences at the Drosophila Notch locus. Cell 1987, 51, 539-548, https://doi.org/10.1016/0092-8674(87)90123-1.

28. Xu, T.; Rebay, I.; Fleming, R.J.; Scottgale, T.N.; Artavanis-Tsakonas, S. The Notch locus and the genetic circuitry involved in early Drosophila neurogenesis. Genes Dev 1990, 4, 464-475, https://doi.org/10.1101/gad.4.3.464.

29. Little, M.H.; Williamson, K.A.; Mannens, M.; Kelsey, A.; Gosden, C.; Hastie, N.D.; van Heyningen, V. Evidence that WT1 mutations in Denys-Drash syndrome patients may act in a dominant-negative fashion. Human molecular genetics 1993, 2, 259-264, https://doi.org/10.1093/hmg/2.3.259. 
30. Hastie, N.D. Dominant negative mutations in the Wilms tumour (WT1) gene cause Denys-Drash syndrome-proof that a tumour-suppressor gene plays a crucial role in normal genitourinary development. Human molecular genetics 1992, 1, 293-295, https://doi.org/10.1093/hmg/1.5.293.

31. Jackson, I.J. Mouse coat colour mutations: a molecular genetic resource which spans the centuries. BioEssays: news and reviews in molecular, cellular and developmental biology 1991, 13, 439-446, https://doi.org/10.1002/bies.950130903.

32. Spritz, R.A.; Holmes, S.A.; Ramesar, R.; Greenberg, J.; Curtis, D.; Beighton, P. Mutations of the KIT (mast/stem cell growth factor receptor) proto-oncogene account for a continuous range of phenotypes in human piebaldism. American journal of human genetics 1992, 51, 1058-1065.

33. Amaya, E.; Musci, T.J.; Kirschner, M.W. Expression of a dominant negative mutant of the FGF receptor disrupts mesoderm formation in Xenopus embryos. Cell 1991, 66, 257-270, https://doi.org/10.1016/00928674(91)90616-7.

34. Vogelstein, B. Cancer. A deadly inheritance. Nature 1990, 348, 681-682, https://doi.org/10.1038/348681a0.

35. Vogelstein, B.; Kinzler, K.W. p53 function and dysfunction. Cell 1992, 70, 523-526, https://doi.org/10.1016/0092-8674(92)90421-8.

36. Milner, J.; Medcalf, E.A. Cotranslation of activated mutant p53 with wild type drives the wild-type p53 protein into the mutant conformation. Cell 1991, 65, 765-774, https://doi.org/10.1016/0092-8674(91)90384b.

37. Veitia, R.A. Exploring the molecular etiology of dominant-negative mutations. The Plant cell 2007, 19, 3843-3851, https://doi.org/10.1105/tpc.107.055053.

38. Benezra, R.; Davis, R.L.; Lockshon, D.; Turner, D.L.; Weintraub, H. The protein Id: a negative regulator of helix-loop-helix DNA binding proteins. Cell 1990, 61, 49-59, https://doi.org/10.1016/0092-8674(90)90214y.

39. Deng, T.; Karin, M. JunB differs from c-Jun in its DNA-binding and dimerization domains, and represses cJun by formation of inactive heterodimers. Genes Dev 1993, 7, 479-490, https://doi.org/10.1101/gad.7.3.479.

40. Harada, H.; Fujita, T.; Miyamoto, M.; Kimura, Y.; Maruyama, M.; Furia, A.; Miyata, T.; Taniguchi, T. Structurally similar but functionally distinct factors, IRF-1 and IRF-2, bind to the same regulatory elements of IFN and IFN-inducible genes. Cell 1989, 58, 729-739, https://doi.org/10.1016/0092-8674(89)90107-4.

41. de Kock, L.; Priest, J.R.; Foulkes, W.D.; Alexandrescu, S. An update on the central nervous system manifestations of DICER1 syndrome. Acta neuropathologica 2020, 139, 689-701, https://doi.org/10.1007/s00401-019-01997-y.

42. Beleggia, F.; Li, Y.; Fan, J.; Elcioğlu, N.H.; Toker, E.; Wieland, T.; Maumenee, I.H.; Akarsu, N.A.; Meitinger, T.; Strom, T.M.; Lang, R.; Wollnik, B. CRIM1 haploinsufficiency causes defects in eye development in human and mouse. Human Molecular Genetics 2015, 24, 2267-2273, https://doi.org/10.1093/hmg/ddu744.

43. Sharma, V.; Sankhyan, A.; Varshney, A.; Choudhary, R.; Sharma, A.K. Current Paradigms to Explore the Gut Microbiota Linkage to Neurological Disorders. Neurology 2020.

44. Rajpoot, M.; Bhattacharya, R.; Sharma, S.; Gupta, S.; Sharma, V.; Sharma, A.K. Melamine contamination and associated health risks: Gut microbiota does make a difference. Biotechnology and applied biochemistry 2020, https://doi.org/10.1002/bab.2050.

45. Flashman, E.; Redwood, C.; Moolman-Smook, J.; Watkins, H. Cardiac myosin binding protein C: its role in $\begin{array}{llllll}\text { physiology and } \text { disease. } & \text { Res } & \text { 2004, } & 94, & 1279-1289 \text {, }\end{array}$ https://doi.org/10.1161/01.res.0000127175.21818.c2.

46. Main, A.; Fuller, W.; Baillie, G.S. Post-translational regulation of cardiac myosin binding protein-C: A graphical review. Cellular signalling 2020, 76, https://doi.org/10.1016/j.cellsig.2020.109788.

47. Rahrmann, E.P.; Moriarity, B.S.; Otto, G.M.; Watson, A.L.; Choi, K.; Collins, M.H.; Wallace, M.; Webber, B.R.; Forster, C.L.; Rizzardi, A.E.; Schmechel, S.C.; Ratner, N.; Largaespada, D.A. Trp53 haploinsufficiency modifies EGFR-driven peripheral nerve sheath tumorigenesis. Am J Pathol 2014, 184, 2082-2098, https://doi.org/10.1016/j.ajpath.2014.04.006.

48. Xiao, H.; Ding, Y.; Gao, Y.; Wang, L.M.; Wang, H.; Ding, L.; Li, X.; Yu, X.; Huang, H. Haploinsufficiency of NR3C1 drives glucocorticoid resistance in adult acute lymphoblastic leukemia cells by down-regulating the mitochondrial apoptosis axis, and is sensitive to Bcl-2 blockage. Cancer Cell Int 2019, 19, https://doi.org/10.1186/s12935-019-0940-9.

49. Pricolo, M.R.; Herrero-Galán, E.; Mazzaccara, C.; Losi, M.A.; Alegre-Cebollada, J.; Frisso, G. Protein Thermodynamic Destabilization in the Assessment of Pathogenicity of a Variant of Uncertain Significance in Cardiac Myosin Binding Protein C. Journal of cardiovascular translational research 2020, 13, 867-877, https://doi.org/10.1007/s12265-020-09959-6.

50. Watkins, H.; Conner, D.; Thierfelder, L.; Jarcho, J.A.; MacRae, C.; McKenna, W.J.; Maron, B.J.; Seidman, J.G.; Seidman, C.E. Mutations in the cardiac myosin binding protein-C gene on chromosome 11 cause familial hypertrophic cardiomyopathy. Nat Genet 1995, 11, 434-437, https://doi.org/10.1038/ng1295-434.

51. Marston, S.; Copeland, O.; Jacques, A.; Livesey, K.; Tsang, V.; McKenna, W.J.; Jalilzadeh, S.; Carballo, S.; Redwood, C.; Watkins, H. Evidence from human myectomy samples that MYBPC3 mutations cause 
hypertrophic cardiomyopathy through haploinsufficiency. Circ Res 2009, 105, 219-222, https://doi.org/10.1161/circresaha.109.202440.

52. Toepfer, C.N.; Wakimoto, H.; Garfinkel, A.C.; McDonough, B.; Liao, D.; Jiang, J.; Tai, A.C.; Gorham, J.M.; Lunde, I.G.; Lun, M.; Lynch, T.L.; McNamara, J.W.; Sadayappan, S.; Redwood, C.S.; Watkins, H.C.; Seidman, J.G.; Seidman, C.E. Hypertrophic cardiomyopathy mutations in MYBPC3 dysregulate myosin. Sci Transl Med 2019, 11, https://doi.org/10.1126/scitranslmed.aat1199.

53. Moolman Johannes, A.; Reith, S.; Uhl, K.; Bailey, S.; Gautel, M.; Jeschke, B.; Fischer, C.; Ochs, J.; McKenna William, J.; Klues, H.; Vosberg, H.-P. A newly created splice donor site in exon 25 of the MyBP$\mathrm{C}$ gene is responsible for inherited hypertrophic cardiomyopathy with incomplete disease penetrance. Circulation 2000, 101, 1396-1402, https://doi.org/10.1161/01.cir.101.12.1396.

54. Rottbauer, W.; Gautel, M.; Zehelein, J.; Labeit, S.; Franz, W.M.; Fischer, C.; Vollrath, B.; Mall, G.; Dietz, R.; Kübler, W.; Katus, H.A. Novel splice donor site mutation in the cardiac myosin-binding protein-C gene in familial hypertrophic cardiomyopathy. Characterization Of cardiac transcript and protein. The Journal of Clinical Investigation 1997, 100, 475-482, https://doi.org/10.1172/jci119555.

55. van Dijk Sabine, J.; Dooijes, D.; dos Remedios, C.; Michels, M.; Lamers Jos, M.J.; Winegrad, S.; Schlossarek, S.; Carrier, L.; ten Cate Folkert, J.; Stienen Ger, J.M.; van der Velden, J. Cardiac MyosinBinding Protein C Mutations and Hypertrophic Cardiomyopathy. Circulation 2009, 119, 1473-1483, https://doi.org/10.1161/circulationaha.108.838672.

56. Izeradjene, K.; Combs, C.; Best, M.; Gopinathan, A.; Wagner, A.; Grady, W.M.; Deng, C.-X.; Hruban, R.H.; Adsay, N.V.; Tuveson, D.A.; Hingorani, S.R Kras(G12D) and Smad4/Dpc4 haploinsufficiency cooperate to induce mucinous cystic neoplasms and invasive adenocarcinoma of the pancreas. Cancer Cell 2007, 11, 229-243, https://doi.org/10.1016/j.ccr.2007.01.017.

57. Sang, L.; Fang, Q.J.; Zhao, X.B. A research on the protein expression of p53, p16, and MDM2 in endometriosis. Medicine (Baltimore) 2019, 98, https://doi.org/10.1097/md.0000000000014776.

58. Xu, J.-Z.; Wang, W.-Q.; Zhang, W.-H.; Xu, H.-X.; Gao, H.-L.; Zhang, S.-R.; Wu, C.-T.; Li, S.; Li, H.; Xu, J.; Yu, X.-J.; Liu, L. The Loss of SMAD4/DPC4 Expression Associated with a Strongly Activated Hedgehog Signaling Pathway Predicts Poor Prognosis in Resected Pancreatic Cancer. J Cancer 2019, 10, 4123-4131, https://doi.org/10.7150/jca.30883.

59. Ruchi Sharma, V.; Kumar Gupta, G.; K Sharma, A.; Batra, N.; K Sharma, D.; Joshi, A.; Sharma, K.A. $\mathrm{PI} 3 \mathrm{~K} / \mathrm{Akt} / \mathrm{mTOR}$ intracellular pathway and breast cancer: factors, mechanism and regulation. Current pharmaceutical design 2017, 23, 1633-1638,

60. Sharma, A.K.; Sharma, V.R.; Gupta, G.K.; Ashraf, G.M.; Kamal, M.A. Advanced glycation end products (AGEs), glutathione and breast cancer: Factors, mechanism and therapeutic interventions. Current drug metabolism 2019, 20, 65-71, https://doi.org/10.2174/1381612823666161116125218.

61. Feilotter, H.E.; Michel, C.; Uy, P.; Bathurst, L.; Davey, S. BRCA1 haploinsufficiency leads to altered expression of genes involved in cellular proliferation and development. PLoS One 2014, 9, https://doi.org/10.1371/journal.pone.0100068.

62. Merajver, S.D.; Pham, T.M.; Caduff, R.F.; Chen, M.; Poy, E.L.; Cooney, K.A.; Weber, B.L.; Collins, F.S.; Johnston, C.; Frank, T.S. Somatic mutations in the BRCA1 gene in sporadic ovarian tumours. Nat Genet 1995, 9, 439-443, https://doi.org/10.1038/ng0495-439.

63. Smith, S.A.; Easton, D.F.; Evans, D.G.; Ponder, B.A. Allele losses in the region 17q12-21 in familial breast and ovarian cancer involve the wild-type chromosome. Nat Genet 1992, 2, 128-131, https://doi.org/10.1038/ng1092-128.

64. Sehrawat, N.; Yadav, M.; Singh, M.; Kumar, V.; Sharma, V.R.; Sharma, A.K. Probiotics in microbiome ecological balance providing a therapeutic window against cancer. Semin Cancer Biol 2020, https://doi.org/10.1016/j.semcancer.2020.06.009.

65. Sørlie, T.; Andersen, T.I.; Bukholm, I.; Børresen-Dale, A.L. Mutation screening of BRCA1 using PTT and $\mathrm{LOH}$ analysis at $17 \mathrm{q} 21$ in breast carcinomas from familial and non-familial cases. Breast Cancer Res Treat 1998, 48, 259-264, https://doi.org/10.1023/a:1005953519972.

66. Futreal, P.A.; Liu, Q.; Shattuck-Eidens, D.; Cochran, C.; Harshman, K.; Tavtigian, S.; Bennett, L.M.; Haugen-Strano, A.; Swensen, J.; Miki, Y. BRCA1 mutations in primary breast and ovarian carcinomas. Science 1994, 266, 120-122, https://doi.org/10.1126/science.7939630.

67. Weinberg, R.A. Tumor suppressor genes. Science 1991, 254, 1138-1146, https://doi.org/10.1126/science.1659741.

68. Joyce, C.; Rayi, A.; Kasi, A. Tumor-Suppressor Genes. In: StatPearls. @ 2020, StatPearls Publishing LLC.: Treasure Island FL, 2020.

69. Weinberg, R.A. Oncogenes and tumor suppressor genes. CA Cancer J Clin 1994, 44, 160-170, https://doi.org/10.3322/canjclin.44.3.160.

70. de Azevedo, J.W.V.; de Medeiros Fernandes, T.A.A.; Fernandes, J.V., Jr.; de Azevedo, J.C.V.; Lanza, D.C.F.; Bezerra, C.M.; Andrade, V.S.; de Araújo, J.M.G.; Fernandes, J.V. Biology and pathogenesis of human osteosarcoma. Oncol Lett 2020, 19, 1099-1116, https://doi.org/10.3892/ol.2019.11229. 
71. Knudson, A.G.Jr. Mutation and cancer: statistical study of retinoblastoma. Proceedings of the National Academy of Sciences of the United States of America 1971, 68, 820-823, https://doi.org/10.1073/pnas.68.4.820.

72. Rodríguez-Martín, C.; Robledo, C.; Gómez-Mariano, G.; Monzón, S.; Sastre, A.; Abelairas, J.; Sábado, C.; Martín-Begué, N.; Ferreres, J.C.; Fernández-Teijeiro, A.; González-Campora, R.; Rios-Moreno, M.J.; Zaballos, Á.; Cuesta, I.; Martínez-Delgado, B.; Posada, M.; Alonso, J. Frequency of low-level and highlevel mosaicism in sporadic retinoblastoma: genotype-phenotype relationships. Journal of human genetics 2020, 65, 165-174, https://doi.org/10.1038/s10038-019-0696-z.

73. Levy, D.B.; Smith, K.J.; Beazer-Barclay, Y.; Hamilton, S.R.; Vogelstein, B.; Kinzler, K.W. Inactivation of both APC alleles in human and mouse tumors. Cancer Res 1994, 54, 5953-5958,

74. Gudmundsson, J.; Johannesdottir, G.; Bergthorsson, J.T.; Arason, A.; Ingvarsson, S.; Egilsson, V.; Barkardottir, R.B. Different tumor types from BRCA2 carriers show wild-type chromosome deletions on 13q12-q13. Cancer Res 1995, 55, 4830-4832.

75. Tory, K.; Brauch, H.; Linehan, M.; Barba, D.; Oldfield, E.; Katz, M.F.; Seizinger, B.; Nakamura, Y.; White, R.; Marshall, F.F.; Lerman, M.I.; Zbar, B. Specific Genetic Change in Tumors Associated With von HippelLindau Disease. JNCI: Journal of the National Cancer Institute 1989, 81, 1097-1101, https://doi.org/10.1093/jnci/81.14.1097.

76. Stapelfeld, C.; Dammann, C.; Maser, E. Sex-specificity in lung cancer risk. Int J Cancer 2020, 146, 23762382, https://doi.org/10.1002/ijc.32716.

77. Levine, A.J. p53: 800 million years of evolution and 40 years of discovery. Nature reviews. Cancer 2020, 20, 471-480, https://doi.org/10.1038/s41568-020-0262-1.

78. Li, G.Z.; Okada, T.; Kim, Y.-M.; Agaram, N.P.; Sanchez-Vega, F.; Shen, Y.; Tsubokawa, N.; Rios, J.; Martin, A.S.; Dickson, M.A.; Qin, L.-X.; Socci, N.D.; Singer, S. Rb and p53-Deficient Myxofibrosarcoma and Undifferentiated Pleomorphic Sarcoma Require Skp2 for Survival. Cancer Res 2020, 80, 2461-2471, https://doi.org/10.1158/0008-5472.can-19-1269.

79. Hollstein, M.; Sidransky, D.; Vogelstein, B.; Harris, C.C. p53 mutations in human cancers. Science 1991, 253, 49-53, https://doi.org/10.1126/science.1905840.

80. Soussi, T.; Béroud, C. Assessing TP53 status in human tumours to evaluate clinical outcome. Nature reviews. Cancer 2001, 1, 233-240, https://doi.org/10.1038/35106009.

81. Tuna, M.; Ju, Z.; Yoshihara, K.; Amos, C.I.; Tanyi, J.L.; Mills, G.B. Clinical relevance of TP53 hotspot mutations in high-grade serous ovarian cancers. $B r \quad J$ Cancer 2020, 122, 405-412, https://doi.org/10.1038/s41416-019-0654-8.

82. Parada, L.F.; Land, H.; Weinberg, R.A.; Wolf, D.; Rotter, V. Cooperation between gene encoding p53 tumour antigen and ras in cellular transformation. Nature 1984, 312, 649-651, https://doi.org/10.1038/312649a0.

83. Jenkins, J.R.; Rudge, K.; Currie, G.A. Cellular immortalization by a cDNA clone encoding the transformation-associated phosphoprotein p53. Nature 1984, 312, 651-654, https://doi.org/10.1038/312651a0.

84. Eliyahu, D.; Raz, A.; Gruss, P.; Givol, D.; Oren, M. Participation of p53 cellular tumour antigen in transformation of normal embryonic cells. Nature 1984, 312, 646-649, https://doi.org/10.1038/312646a0.

85. Xue, W.; Zender, L.; Miething, C.; Dickins, R.A.; Hernando, E.; Krizhanovsky, V.; Cordon-Cardo, C.; Lowe, S.W. Senescence and tumour clearance is triggered by p53 restoration in murine liver carcinomas. Nature 2007, 445, 656-660, https://doi.org/10.1038/nature05529.

86. Finlay, C.A.; Hinds, P.W.; Levine, A.J. The p53 proto-oncogene can act as a suppressor of transformation. Cell 1989, 57, 1083-1093, https://doi.org/10.1016/0092-8674(89)90045-7.

87. Levine, A.J.; Momand, J.; Finlay, C.A. The p53 tumour suppressor gene. Nature 1991, 351, 453-456, https://doi.org/10.1038/351453a0.

88. Stein, Y.; Rotter, V.; Aloni-Grinstein, R. Gain-of-Function Mutant p53: All the Roads Lead to Tumorigenesis. Int J Mol Sci 2019, 20, https://doi.org/10.3390/ijms20246197.

89. Sheehan, C.J.; McMahon, J.J.; Serdar, L.D.; Silver, D.L. Dosage-dependent requirements of Magoh for cortical interneuron generation and survival. Development (Cambridge, England) 2020, 147, https://doi.org/10.1242/dev.182295.

90. Varley, J.M.; Evans, D.G.; Birch, J.M. Li-Fraumeni syndrome--a molecular and clinical review. Br J Cancer 1997, 76, 1-14, https://doi.org/10.1038/bjc.1997.328.

91. Srivastava, S.; Zou, Z.Q.; Pirollo, K.; Blattner, W.; Chang, E.H. Germ-line transmission of a mutated p53 gene in a cancer-prone family with Li-Fraumeni syndrome. Nature 1990, 348, 747-749, https://doi.org/10.1038/348747a0.

92. Malkin, D.; Li, F.P.; Strong, L.C.; Fraumeni, J.F., Jr.; Nelson, C.E.; Kim, D.H.; Kassel, J.; Gryka, M.A.; Bischoff, F.Z.; Tainsky, M.A. Germ line p53 mutations in a familial syndrome of breast cancer, sarcomas, and other neoplasms. Science 1990, 250, 1233-1238, https://doi.org/10.1126/science.1978757.

93. Rafei, H.; DiNardo, C.D. Hereditary myeloid malignancies. Best practice \& research. Clinical haematology 2019, 32, 163-176, https://doi.org/10.1016/j.beha.2019.05.001. 
94. Venkatachalam, S.; Shi, Y.P.; Jones, S.N.; Vogel, H.; Bradley, A.; Pinkel, D.; Donehower, L.A. Retention of wild-type p53 in tumors from p53 heterozygous mice: reduction of p53 dosage can promote cancer formation. The EMBO journal 1998, 17, 4657-4667, https://doi.org/10.1093/emboj/17.16.4657.

95. Chu, B.; Kon, N.; Chen, D.; Li, T.; Liu, T.; Jiang, L.; Song, S.; Tavana, O.; Gu, W. ALOX12 is required for p53-mediated tumour suppression through a distinct ferroptosis pathway. Nature cell biology 2019, 21, 579591, https://doi.org/10.1038/s41556-019-0305-6.

96. Gottlieb, E.; Haffner, R.; King, A.; Asher, G.; Gruss, P.; Lonai, P.; Oren, M. Transgenic mouse model for studying the transcriptional activity of the p53 protein: age- and tissue-dependent changes in radiationinduced activation during embryogenesis. The EMBO journal 1997, 16, 1381-1390, https://doi.org/10.1093/emboj/16.6.1381.

97. McTiernan, A.; Friedenreich, C.M.; Katzmarzyk, P.T.; Powell, K.E.; Macko, R.; Buchner, D.; Pescatello, L.S.; Bloodgood, B.; Tennant, B.; Vaux-Bjerke, A.; George, S.M.; Troiano, R.P.; Piercy, K.L. Physical Activity in Cancer Prevention and Survival: A Systematic Review. Medicine and science in sports and exercise 2019, 51, 1252-1261, https://doi.org/10.1249/mss.0000000000001937.

98. Nardella, C.; Chen, Z.; Salmena, L.; Carracedo, A.; Alimonti, A.; Egia, A.; Carver, B.; Gerald, W.; CordonCardo, C.; Pandolfi, P.P. Aberrant Rheb-mediated mTORC1 activation and Pten haploinsufficiency are cooperative oncogenic events. Genes Dev 2008, 22, 2172-2177, https://doi.org/10.1101/gad.1699608.

99. Sharma, A.; Indu, S.; Gautami, D.; Sharma, D. Oral squamous cell carcinoma (OSCC) in humans: Etiological Factors, diagnostic and therapeutic relevance. Research Journal of Biotechnology 2020, 15, 141-151.

100. Carver, B.S.; Tran, J.; Gopalan, A.; Chen, Z.; Shaikh, S.; Carracedo, A.; Alimonti, A.; Nardella, C.; Varmeh, S.; Scardino, P.T.; Cordon-Cardo, C.; Gerald, W.; Pandolfi, P.P. Aberrant ERG expression cooperates with loss of PTEN to promote cancer progression in the prostate. Nat Genet 2009, 41, 619-624, https://doi.org/10.1038/ng.370.

101. Ali, I.U. Gatekeeper for endometrium: the PTEN tumor suppressor gene. J Natl Cancer Inst 2000, 92, 861863, https://doi.org/10.1093/jnci/92.11.861.

102. Kinzler, K.W.; Vogelstein, B. Cancer-susceptibility genes. Gatekeepers and caretakers. Nature 1997, 386, 761-763, https://doi.org/10.1038/386761a0.

103. Sharma, V.; Panwar, A.; Sharma, A.K. Molecular Dynamic Simulation Study on Chromones and Flavonoids for the In Silico Designing of a Potential Ligand Inhibiting mTOR Pathway in Breast Cancer. Current Pharmacology Reports 2020, https://doi.org/10.1007/s40495-020-00246-1.

104. Sharma, D.; Sharma, A. An In-Silico Approach for Designing a Potential Antagonistic Molecule Targeting 3 2-adrenoreceptor Having Therapeutic Significance. Letters in Applied NanoBioScience 2021, 10, 20632069.

105. Chen, Z.; Trotman, L.C.; Shaffer, D.; Lin, H.-K.; Dotan, Z.A.; Niki, M.; Koutcher, J.A.; Scher, H.I.; Ludwig, T.; Gerald, W.; Cordon-Cardo, C.; Paolo Pandolfi, P. Crucial role of p53-dependent cellular senescence in suppression of Pten-deficient tumorigenesis. Nature 2005, 436, 725-730, https://doi.org/10.1038/nature03918.

106. Salmena, L.; Carracedo, A.; Pandolfi, P.P. Tenets of PTEN tumor suppression. Cell 2008, 133, 403-414, https://doi.org/10.1016/j.cell.2008.04.013.

107. Mukta Raghav, V.S., Mayank Chaudhary, Hardeep Singh Tuli, Adesh K. Saini, Anil K. Sharma The essence of PTEN: a broad-spectrum therapeutic target in cancer. Biointerface Research in Applied Chemistry. 2021, 11, 9587-9603, https://doi.org/10.33263/BRIAC112.95879603.

108. Alimonti, A.; Nardella, C.; Chen, Z.; Clohessy, J.G.; Carracedo, A.; Trotman, L.C.; Cheng, K.; Varmeh, S.; Kozma, S.C.; Thomas, G.; Rosivatz, E.; Woscholski, R.; Cognetti, F.; Scher, H.I.; Pandolfi, P.P. A novel type of cellular senescence that can be enhanced in mouse models and human tumor xenografts to suppress prostate tumorigenesis. J Clin Invest 2010, 120, 681-693, https://doi.org/10.1172/jci40535.

109. Ma, L.; Teruya-Feldstein, J.; Behrendt, N.; Chen, Z.; Noda, T.; Hino, O.; Cordon-Cardo, C.; Pandolfi, P.P. Genetic analysis of Pten and Tsc2 functional interactions in the mouse reveals asymmetrical haploinsufficiency in tumor suppression. Genes Dev 2005, 19, 1779-1786, https://doi.org/10.1101/gad.1314405.

110. Quintás-Cardama, A.; Post, S.M.; Solis, L.M.; Xiong, S.; Yang, P.; Chen, N.; Wistuba, II; Killary, A.M.; Lozano, G. Loss of the novel tumour suppressor and polarity gene Trim62 (Dear1) synergizes with oncogenic Ras in invasive lung cancer. J Pathol 2014, 234, 108-119, https://doi.org/10.1002/path.4385.

111. Sharma, V.; Sharma, A.K.; Punj, V.; Priya, P. Recent nanotechnological interventions targeting PI3K/Akt/mTOR pathway: A focus on breast cancer. Semin Cancer Biol 2019, 59, 133-146, https://doi.org/10.1016/j.semcancer.2019.08.005.

112. Wan, R.; Crowe, D.L. Haploinsufficiency of the Nijmegen breakage syndrome 1 gene increases mammary tumor latency and metastasis. International journal of oncology 2012, 41, 345-352, https://doi.org/10.3892/ijo.2012.1435

113. Cho, S.G.; Wang, Y.; Rodriguez, M.; Tan, K.; Zhang, W.; Luo, J.; Li, D.; Liu, M. Haploinsufficiency in the prometastasis Kiss 1 receptor Gpr54 delays breast tumor initiation, progression, and lung metastasis. Cancer Res 2011, 71, 6535-6546, https://doi.org/10.1158/0008-5472.can-11-0329. 
114. Richard, S.; Vogel, G.; Huot, M.E.; Guo, T.; Muller, W.J.; Lukong, K.E. Sam68 haploinsufficiency delays onset of mammary tumorigenesis and metastasis. Oncogene 2008, 27, 548-556, https://doi.org/10.1038/sj.onc.1210652.

115. Iwakuma, T.; Tochigi, Y.; Van Pelt, C.S.; Caldwell, L.C.; Terzian, T.; Parant, J.M.; Chau, G.P.; Koch, J.G.; Eischen, C.M.; Lozano, G. Mtbp haploinsufficiency in mice increases tumor metastasis. Oncogene 2008, 27, 1813-1820, https://doi.org/10.1038/sj.onc.1210827.

116. Alimonti, A.; Carracedo, A.; Clohessy, J.G.; Trotman, L.C.; Nardella, C.; Egia, A.; Salmena, L.; Sampieri, K.; Haveman, W.J.; Brogi, E.; Richardson, A.L.; Zhang, J.; Pandolfi, P.P. Subtle variations in Pten dose determine cancer susceptibility. Nat Genet 2010, 42, 454-458, https://doi.org/10.1038/ng.556.

117. Hemann, M.T.; Fridman, J.S.; Zilfou, J.T.; Hernando, E.; Paddison, P.J.; Cordon-Cardo, C.; Hannon, G.J.; Lowe, S.W. An epi-allelic series of p53 hypomorphs created by stable RNAi produces distinct tumor phenotypes in vivo. Nat Genet 2003, 33, 396-400, https://doi.org/10.1038/ng1091.

118. Ebert, B.L. Deletion $5 q$ in myelodysplastic syndrome: a paradigm for the study of hemizygous deletions in cancer. Leukemia 2009, 23, 1252-1256, https://doi.org/10.1038/leu.2009.53.

119. Xue, W.; Kitzing, T.; Roessler, S.; Zuber, J.; Krasnitz, A.; Schultz, N.; Revill, K.; Weissmueller, S.; Rappaport, A.R.; Simon, J.; Zhang, J.; Luo, W.; Hicks, J.; Zender, L.; Wang, X.W.; Powers, S.; Wigler, M.; Lowe, S.W. A cluster of cooperating tumor-suppressor gene candidates in chromosomal deletions. Proceedings of the National Academy of Sciences of the United States of America 2012, 109, 8212-8217, https://doi.org/10.1073/pnas.1206062109.

120. de Pontual, L.; Yao, E.; Callier, P.; Faivre, L.; Drouin, V.; Cariou, S.; Van Haeringen, A.; Geneviève, D.; Goldenberg, A.; Oufadem, M.; Manouvrier, S.; Munnich, A.; Vidigal, J.A.; Vekemans, M.; Lyonnet, S.; Henrion-Caude, A.; Ventura, A.; Amiel, J. Germline deletion of the miR-17 92 cluster causes skeletal and growth defects in humans. Nat Genet 2011, 43, 1026-1030, https://doi.org/10.1038/ng.915.

121. Grosshans, H.; Büssing, I. MicroRNA biogenesis takes another single hit from microsatellite instability. Cancer Cell 2010, 18, 295-297, https://doi.org/10.1016/j.ccr.2010.10.005.

122. Kumar, M.S.; Pester, R.E.; Chen, C.Y.; Lane, K.; Chin, C.; Lu, J.; Kirsch, D.G.; Golub, T.R.; Jacks, T. Dicer1 functions as a haploinsufficient tumor suppressor. Genes Dev 2009, 23, 2700-2704, https://doi.org/10.1101/gad.1848209.

123. Bartel, D.P. MicroRNAs: target recognition and regulatory functions. Cell 2009, 136, 215-233, https://doi.org/10.1016/j.cell.2009.01.002. 